\title{
HOMOGENEOUS FOCUSING FIELD FOR SHORT RELATIVISTIC ELECTRON BUNCHES IN PLASMA
}

\author{
V.I. Maslov ${ }^{1,2}$, I.P. Levchuk ${ }^{1}$, D.S. Bondar ${ }^{1,2}$, I.N. Onishchenko ${ }^{1}$ \\ ${ }^{1}$ National Science Center “Kharkov Institute of Physics and Technology”, Kharkiv, Ukraine; \\ ${ }^{2}$ V.N. Karazin Kharkiv National University, Kharkiv, Ukraine
}

Plasma wake lens in which all short relativistic electron bunches of sequence are focused identically and uniformly is studied analytically and by numerical simulation. For two types of lenses necessary parameters of focused sequence of relativistic electron bunches are formulated. Verification of these parameters is performed by numerical simulation.

PACS: 29.17.+w; 41.75.Lx

\section{INTRODUCTION}

As plasma in experiment is inhomogeneous and nonstationary and properties of wakefield changes at increase of its amplitude it is difficult to excite wakefield resonantly by a long sequence of electron bunches (see $[1,2]$ ), to focus sequence (see [3 - 8]), to prepare sequence from long beam (see [9 - 11]) and to provide large transformer ratio (see [12 - 18]). Providing a large transformer ratio is also being studied in dielectric accelerators (see [19 - 24]). In [2] the mechanism has been found and in [25 - 29] investigated of resonant plasma wakefield excitation by a nonresonant sequence of short electron bunches.

In [30 - 33] it has shown that at certain conditions the laser wakefield acceleration is added by a beamplasma wakefield acceleration.

In [34] point self-injected and accelerated electron bunch was observed.

In numerical simulation [33] on wakefield excitation by a x-ray laser pulse in a metallic-density electron plasma the accelerating gradient of several $\mathrm{TV} / \mathrm{m}$ has been obtained.

Focusing of relativistic electron bunches of sequence by wakefield, excited in the plasma, is important and interesting (see [35, 36 - 46]). Mechanism of focusing in the plasma, in which all bunches of sequence are focused identically and uniformly, is proposed and investigated by numerical simulation in [3, 4]. This plasma wake lens for short relativistic electron bunches is studied in this paper analytically and by numerical simulation by code lcode [47]. Unbounded nonmagnetized homogeneous plasma is considered. The rectangular in longitudinal direction bunches (i.e. the bunch current is const along bunch axis) are considered in the fixed their current approximation.

The purpose of this paper is to show analytically and by numerical simulation that one can derive and achieve conditions of identical and uniform focusing of sequence of short relativistic electron bunches.

\section{HOMOGENEOUS FOCUSING FIELD FOR SEQUENCE OF SHORT BUNCHES}

Plasma wake lens with a uniform focusing force for sequence of bunches, whose lengths are equal to half of the excited wavelength $\xi_{\mathrm{b}}=\lambda / 2$, with the first bunch, whose charge is in 2 times less than the charges of other bunches $\mathrm{Q}_{1}=\mathrm{Q}_{\mathrm{i}} / 2, \mathrm{i}=2,3, \ldots$, the space interval between bunches equals $\lambda$, has been numerically simulated in $[3,4]$. We consider a homogeneous focusing of sequence of short bunches.

At first we will derive the wakefield inside the 2nd bunch, the charge of which is more in B times than the charge of the first bunch. We take into account that between the newly generated wakefield and wakefield, formed by previous bunch, is the phase difference A. Then in the second rectangular in longitudinal direction bunch (i.e. the bunch current is const along bunch axis) we have

$$
\begin{gathered}
\mathrm{E}_{\mathrm{z}} \propto \mathrm{Z}_{\mathrm{z}}(\xi)=(1 / \mathrm{k}) \sqrt{2} \cos (\mathrm{k} \xi-\pi / 4+\mathrm{A})+ \\
+\mathrm{B} \int_{0}^{\xi} \mathrm{d} \xi_{0} \cos \left[\mathrm{k}\left(\xi-\xi_{0}\right)\right]= \\
=(1 / \mathrm{k})\{\sqrt{2} \cos (\mathrm{k} \xi-\pi / 4+\mathrm{A})+\mathrm{B} \sin (\mathrm{k} \xi)\} .
\end{gathered}
$$

$Z_{z}(\xi)$ becomes zero, if $B=\sqrt{2}$ and $A=3 \pi / 4$.

The same $Z_{z}(\xi)$ is occurred in each of the following bunches, if they are spaced apart by a $\mathrm{k} \delta \xi=2 \pi$.

Now we will derive the wakefield inside the 2 nd short bunch, $\xi_{\mathrm{b}}=\lambda / 4$, charge of which is in 2 times more than the charge of 1 st bunch, the space interval between it and the first bunch is equal to $\delta \xi=\lambda$. We take into account that between the newly generated wakefield and wakefield, formed by previous bunch, is the phase difference $\pi$. Then in the 2 nd bunch we have

$$
\begin{gathered}
\mathrm{E}_{\mathrm{z}} \propto \mathrm{Z}_{\mathrm{z}}(\xi)=(2 / \mathrm{k}) \sin (\mathrm{x}+\pi)+2 \int_{0}^{\xi} \mathrm{d} \xi_{0} \cos \left[\mathrm{k}\left(\xi-\xi_{0}\right)\right]=0, \\
\mathrm{E}_{\mathrm{r}} \propto \mathrm{Z}_{\mathrm{r}}(\xi)=-(2 / \mathrm{k}) \cos (\mathrm{x}+\pi)+2 \int_{0}^{\xi} \mathrm{d} \xi_{0} \sin \left[\mathrm{k}\left(\xi-\xi_{0}\right)\right]=2 / \mathrm{k} .
\end{gathered}
$$

The same $Z_{\mathrm{z}}(\xi)$ and $Z_{\mathrm{r}}(\xi)$ are occurred inside the all next bunches, which are identical to 2 nd bunch. From Figs. 1 and 2 one can see that $\mathrm{E}_{\mathrm{z}}=0$ in the bunch location areas.

From Figs. 1-4 one can see that in the areas of bunch location $\mathrm{F}_{\mathrm{r}}$ approximately does not depend on the longitudinal coordinate.

We consider now the focusing fields, which are formed in the areas of location of short bunches of sequence (with a certain bunch - precursor) at shaping of their charge linearly along the sequence as well as along each bunch. From Fig. 5 one can see that the bunches are in small and approximately identical decelerating fields and maximal focusing fields.

We consider now focusing field, which is formed in the area of location of a continuous beam, the front of which is a half-step density of length of the half- 
wavelength (Fig. 6).

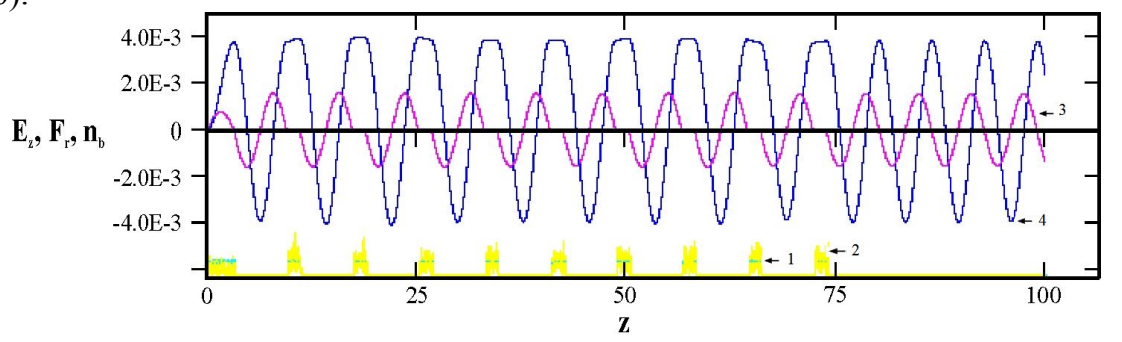

Fig. 1. The longitudinal distribution of bunch radius (1), density $n_{b}$ of bunches (2), $E_{z}(3)$ and $F_{r}(4)$, excited by sequence of bunches, length of the 1 st bunch is equal to $\Delta \xi_{b I}=\lambda / 2$, all other bunches are short, $\Delta \xi_{b}=\lambda / 4$, the charge density of all other bunches is in two times larger than the charge of 1st bunch, space intervals between all bunches are equal to $\delta \xi=\lambda$. The longitudinal coordinate $z$ is normalized on $2 \pi / \lambda . E_{z}$ and $F_{r}$ are normalized on $m c \omega_{p e} / e . e, m$ are the charge and mass of the electron, $c$ is the light velocity, $\omega_{p e}$ is the electron plasma frequency

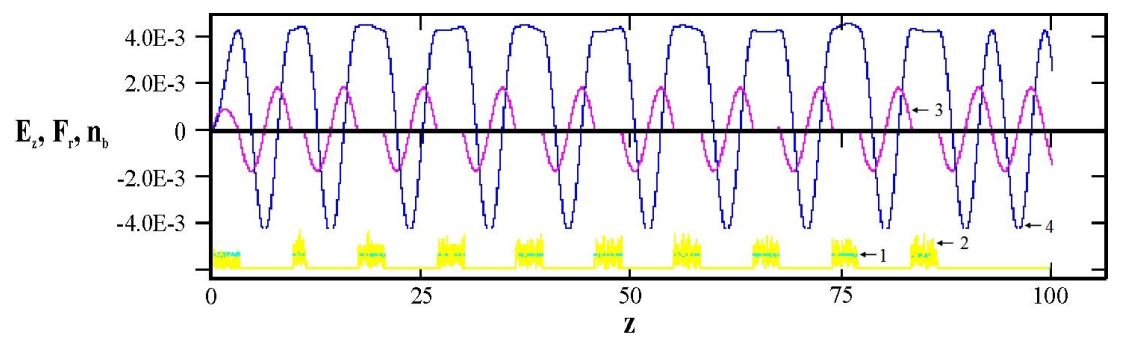

Fig. 2. The longitudinal distribution of bunch radius (1), density $n_{b}$ of bunches (2), $E_{z}(3)$ and $F_{r}(4)$, excited by sequence of bunches, the length of 2 nd bunch is equal to $\Delta \xi_{b I}=\lambda / 4$, lengths of the other bunches are $\Delta \xi_{b I}=\lambda / 2$, the charge density of all other bunches is in two times larger than the charge density of 1st bunch, the space intervals between all bunches are equal to $\delta \xi=\lambda$

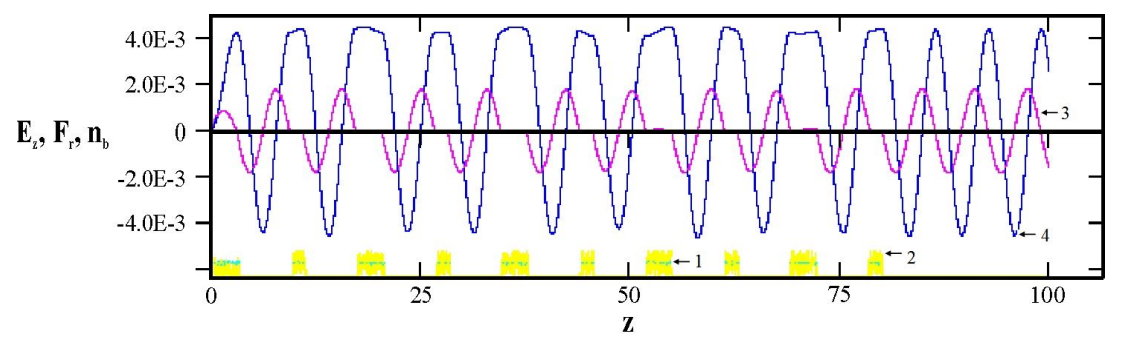

Fig. 3. The longitudinal distribution of bunch radius (1), density $n_{b}$ of bunches (2), $E_{z}(3)$ and $F_{r}(4)$, excited by sequence of bunches, the length of even bunches is equal to $\Delta \xi_{b 2}=\lambda / 4$, and the length of uneven bunches is equal to $\Delta \xi_{b}=\lambda / 2$, the charge density of all other bunches is in two times larger than the charge density of 1 st bunch,

the space intervals between all bunches are equal to $\delta \xi=\lambda$



Fig. 4. The longitudinal distribution of bunch radius (1), density $n_{b}$ of bunches (2), $E_{z}(3)$ and $F_{r}(4)$, excited by sequence of bunches; the charges of bunches are in $\sqrt{2}$ times larger than the charge of 1st bunch, the space interval between 1 st and 2 nd bunches is equal to $\lambda 9 / 8$, the space interval between other bunches is equal to $\lambda$

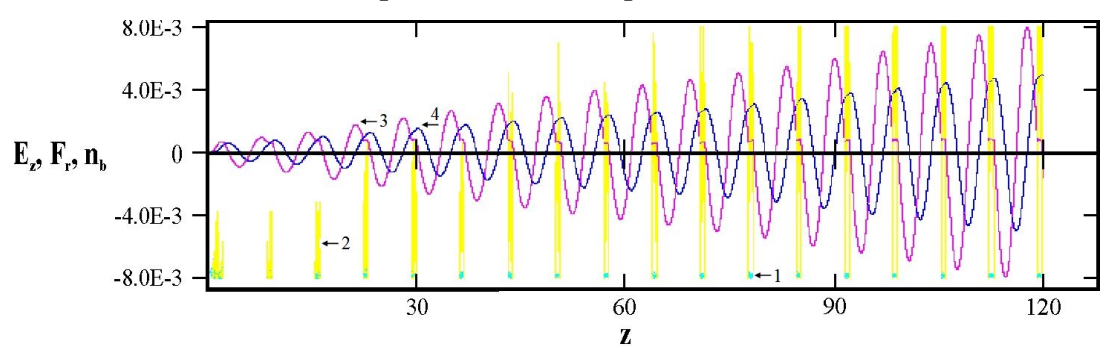


Fig. 5. The longitudinal distribution of bunch radius (1), density $n_{b}$ of bunches (2), longitudinal wakefield $E_{z}$ (3) and focusing field $F_{r}(4)$, excited by sequence of short bunches (with a certain bunch - precursor) at shaping of their charge linearly along the sequence as well as along each bunch

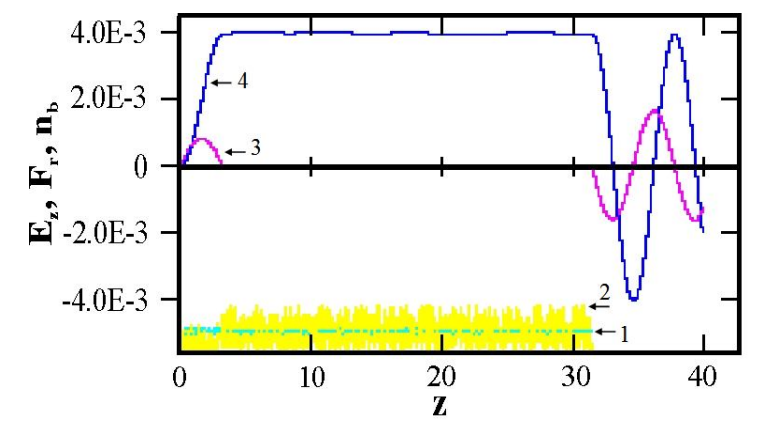

Fig. 6. The longitudinal distribution of beam radius (1), density $n_{b}$ of beam (2), longitudinal wakefield $E_{z}(3)$ and focusing field $F_{r}(4)$, excited by a continuous beam the front of which is a step

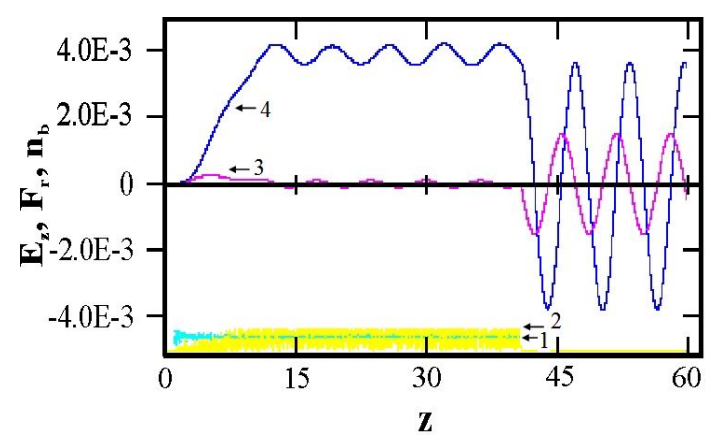

Fig. 7. The longitudinal distribution of beam radius (1), density $n_{b}$ of beam (2), longitudinal wakefield $E_{z}$ (3) and focusing field $F_{r}(4)$, excited by a continuous beam with a smooth front, the length of which is equal to two wavelengths

One can see that along the whole beam the focusing field is identical (homogeneous). The focusing field reaches its maximal value at the short spatial interval coinciding with the length of the beam front.

Such a uniform focusing field along the beam is not reached (Fig. 7) in the case of a smooth beam density increase along beam front.

\section{CONCLUSIONS}

It has been shown that all bunches of sequences can be focused identically and uniformly. It has been shown that there are two types of lenses for a sequence of short bunches. It is necessary that in one case the length of the 1 st bunch $\Delta \xi_{\mathrm{b} 1}$ should be equal to half of the wavelength $\Delta \xi_{\mathrm{b} 1}=\lambda / 2$, all other bunches are short, $\Delta \xi_{\mathrm{b}}<\lambda / 2$, the charge density of all other bunches is in 2 times larger than the charge density of the 1st bunch. The space intervals between all bunches should be multiples of the wavelength $\delta \xi=\mathrm{p} \lambda, \mathrm{p}=1,2, \ldots$ for achievement of: $E_{z}=0$; radial focusing field is the same along the bunch $\mathrm{F}_{\mathrm{r}}=$ const in areas of location of bunches.

In the second case it is necessary that the charges of all bunches are in $\sqrt{2}$ times larger than the charge of 1 st bunch. The space interval between the 1 st and 2 nd bunches is equal to $(n+1 / 8) \lambda, n=1,2, \ldots$ The space interval between the other bunches is multiple to wave- length. It has been shown analytically that only 1 st bunch is in the finite $\mathrm{E}_{\mathrm{z}} \neq 0$. Other bunches are in zero longitudinal electric wakefield $\mathrm{E}_{\mathrm{z}}=0$. Consequently, the 1 -st bunch exchanges by energy with wakefield. Next bunches do not exchange by energy with the wakefield. Wakefield radial force $F_{r}$ is the same approximately along the bunch. The focusing field of this value is formed in now widely investigated plasma lens for a long relativistic electron beam.

\section{REFERENCES}

1. K.V. Lotov, V.I. Maslov, I.N. Onishchenko, et al. Simulation of plasma wakefield excitation by a sequence of electron bunches // Problems of Atomic Science and Technology. 2008, № 6, p. 114-116.

2. K.V. Lotov, V.I. Maslov, I.N. Onishchenko, et al. Resonant excitation of plasma wakefield by a nonresonant train of short electron bunches // Plasma Phys. Cont. Fus. 2010, v. 52, № 6, p. 065009.

3. K.V. Lotov, V.I. Maslov, I.N. Onishchenko, et al. Homogeneous Focusing of Electron Bunch Sequence by Plasma Wakefield // Problems of Atomic Science and Technology. 2012, № 3, p. 159-163.

4. V.I. Maslov, I.N. Onishchenko, I.P. Yarovaya. Plasma Wakefield Excitation, Possessing of Homogeneous Focusing of Electron Bunches // Problems of Atomic Science and Technology. 2013, № 1, p. 134-136.

5. V.I. Maslov, I.N. Onishchenko, I.P. Yarovaya. Fields excited and providing a uniform focusing of short relativistic electron bunches in plasma // East European Journal of Physics. 2014, v. 1, № 2, p. 92-95.

6. I.P. Levchuk, V.I. Maslov, I.N. Onishchenko. Focusing of Relativistic Electron Bunches by Nonresonant Wakefield Excited in Plasma // Problems of Atomic Science and Technology. 2015, № 4, p. $120-123$.

7. I.P. Levchuk, V.I. Maslov, I.N. Onishchenko. Focusing by Wakefield and Plasma Focusing of Relativistic Electrons in Dependence on Parameters of Experiments // Problems of Atomic Science and Technology. 2016, № 3, p. 62-65.

8. V.I. Maslov et al. Uniform Focusing of Train of Relativistic Positron Bunches in Plasma // East Eur. J. Phys. 2019, № 2, p. 69-74.

9. K.V. Lotov, V.I. Maslov, I.N. Onishchenko, et al. 2d3v Numerical Simulation of Instability of Cylindrical Relativistic Electron Beam in Plasma // Problems of Atomic Science and Technology. 2010, № 4, p. 12-16.

10. K.V. Lotov, V.I. Maslov, I.N. Onishchenko, et al. To the Mechanism of Instability of Cylindrical Relativistic Electron Beam in Plasma // Problems of Atomic Science and Technology. 2011, № 1, p. 8385. 
11. V.A. Balakirev, I.N. Onishchenko, V.I. Maslov. Instability of finite radius relativistic electron beam in plasma // Problems of Atomic Science and Technology. 2011, № 3, p. 92-95.

12. K.V. Lotov, V.I. Maslov, I.N. Onishchenko. Transformer Ratio in Wake-Field Method of Acceleration for Sequence of Relativistic Electron Bunches // Problems of Atomic Science and Technology. 2010, № 4, p. 85-89.

13. K.V. Lotov, V.I. Maslov, I.N. Onishchenko, I.P. Yarovaya. Transformer Ratio at Interaction of Long Sequence of Electron Bunches with Plasma // Problems of Atomic Science and Technology. 2011, № 3, p. 87-91.

14. V.I. Maslov, I.N. Onishchenko, I.P. Yarovaya. Transformer Ratio at Excitation of Nonlinear Wakefield in Plasma by Shaped Sequence of Electron Bunches with Linear Growth of Charge // Problems of Atomic Science and Technology. 2012, № 4, p. 128-130.

15. V.I. Maslov, I.N. Onishchenko, I.P. Yarovaya. Wakefield Excitation in Plasma by Sequence of Shaped Electron Bunches // Problems of Atomic Science and Technology. 2012, № 6, p. 161-163.

16. I.P. Levchuk, V.I. Maslov, I.N. Onishchenko. Transformer Ratio at Wakefield Excitation by Linearly Shaped Sequence of Short Relativistic Electron Bunches // Problems of Atomic Science and Technology. 2015, № 6, p. 37-41.

17. I.P. Levchuk, V.I. Maslov, I.N. Onishchenko. Transformer Ratio at Wakefield Excitation in Dissipative Media by Sequence of Electron Bunches // Problems of Atomic Science and Technology. 2017, № 6, p. 43-46.

18. D.S. Bondar, I.P. Levchuk, V.I. Maslov, I.N. Onishchenko. Transformer Ratio Dependence on Bunch Length at Non-Linear Wakefield Excitation in Plasma by Electron Bunch with Gaussian Charge Distribution // East Eur. J. Phys. 2018, v. 5, № 2, p. $72-77$.

19. V.I. Maslov, I.N. Onishchenko. Transformer Ratio at Wakefield Excitation in Dielectric Resonator by Shaped Sequence of Electron Bunches with Linear Growth of Current // Problems of Atomic Science and Technology. 2013, № 4, p. 69-72.

20. V.I. Maslov, I.N. Onishchenko. Transformer Ratio at Wakefield Acceleration in Dielectric Resonator // Problems of Atomic Science and Technology. 2014, № 3, p. 99-101.

21. V.I. Maslov, I.N. Onishchenko. Transformer Ratio at Wakefield Excitation in Dielectric Resonator by Sequence of Rectangular Electron Bunches with Linear Growth of Charge // Problems of Atomic Science and Technology. 2014, № 3, p. 95-98.

22. V.I. Maslov, I.N. Onishchenko. To transformer ratio in resonator concept of dielectric wakefield accelerator driven by a tailored sequence of electron bunches // Proc. of the 9th Int. Workshop "Strong Microwaves and Terahertz Waves: Sources and Ap- plications". Nizhny Novgorod, 24-30 July 2014, 2 p.

23. G.P. Berezina, A.F. Linnik, V.I. Maslov, et al. Transformer Ratio Increase at Wakefield Excitation in the Dielectric Structure by a Shaped Sequence of Relativistic Electron Bunches // Problems of Atomic Science and Technology. 2016, № 3, p. 69-73.

24. V.I. Maslov et al. Effect of Transition Radiation and Dispersion Spreading at Achievement of a Large Transformer Ratio of Exciting Bunch Energy into Wakefield in a Dielectric Resonator Accelerator // Problems of Atomic Science and Technology. 2019, № 4, p. 48-54.

25. K.V. Lotov, V.I. Maslov, I.N. Onishchenko, et al. 2.5D simulation of plasma wakefield excitation by a nonresonant chain of relativistic electron bunches // Problems of Atomic Science and Technology. 2010, № 2, p. 122-124.

26. V. Lotov, V.I. Maslov, I.N. Onishchenko, et al. To Plasma Wakefield Excitation by a Nonresonant Sequence of Relativistic Electron Bunches at Plasma Frequency above Bunch Repetition Frequency // Problems of Atomic Science and Technology. 2010, № 6, p. 114-116.

27. K.V. Lotov, V.I. Maslov, I.N. Onishchenko. Long Sequence of Relativistic Electron Bunches as a Driver in Wakefield Method of Charged Particles Acceleration in Plasma // Problems of Atomic Science and Technology. 2010, № 6, p. 103-107.

28. K.V. Lotov, V.I. Maslov, I.N. Onishchenko, I.P. Yarovaya. Mechanisms of Synchronization of Relativistic Electron Bunches at Wakefield Excitation in Plasma // Problems of Atomic Science and Technology. 2013, № 4, p. 73-76.

29. V.I. Maslov et al. Optimal Resonant Asymptotics of Wakefield Excitation in Plasma by Non-resonant Sequence of Relativistic Electron Bunches // Problems of Atomic Science and Technology. 2019, № 1, p. 99.

30. V.I. Maslov, O.M. Svystun, I.N. Onishchenko, et al. Dynamics of Electron Bunches at the Laser-Plasma Interaction in the Bubble Regime // Nuclear Instruments and Methods in Physics Research A. 2016, v. 829 , p. 422-425.

31. V.I. Maslov, O.M. Svystun, I.N. Onishchenko, et al. Joint Wakefield Acceleration by Laser Pulse and by Self-Injected Electron Bunches // Problems of Atomic Science and Technology. 2016, № 6, p. 144147.

32. D.S. Bondar, I.P. Levchuk, V.I. Maslov, et al. Dynamics of Self-Injected Electron Bunches at their Acceleration by Laser Pulse in Plasma // Problems of Atomic Science and Technology. 2017, № 6, p. 76-79.

33. D.S. Bondar, V.I. Maslov, I.P. Levchuk, I.N. Onishchenko. Excitation of Wakefield by a Laser Pulse in a Metal Density Plasma // Problems of Atomic Science and Technology. 2018, № 6, p. 156159. 
34. V.I. Maslov et al. Improvement of Properties of Self-Injected and Accelerated Electron Bunch by Laser Pulse in Plasma, Using Pulse Precursor // East Eur. J. Phys. 2019, № 2, p. 64-68.

35. Ya. Fainberg, M. Ayzatsky, V. Balakirev, et al. Focusing of Relativistic Electron Bunches at the Wakefield Excitation in Plasma // Proc. PAC'97. 12-16 May, 1997, Vancouver, Canada, v. II, p. 651653.

36. C. O'Connell et al. // Phys. Rev. Accel. \& Beams. 2002, v. 5, p. 121301.

37. M.C. Tompson et al. CP877, Adv. Accel. Concepts 12 Workshop. 2006, p. 561.

38. M.C. Tompson et al. Observations of low-aberration plasma lens focusing of relativistic electron beams at the underdense threshold // Phys. Plasmas. 2010, v. 17, p. 073105.

39. S.Yu. Kalmykov et al. // Phys. Plas. 2006, v. 13, p. 113102.

40. M.J. Hogan, C.E. Clayton, C. Huang, et al. Ultrarelativistic-Positron-Beam Transport through MeterScale Plasmas // Phys. Rev. Lett. 2003, v. 90, № 20, p. 205002.

41. P. Muggli, B.E. Blue, C.E. Clayton, et al. Halo Formation and Emittance Growth of Positron Beams in Plasmas // Phys. Rev. Lett. 2008, v. 101, p. 055001.
42. M. Reiser, H. Li. Solutions of the matched kV envelope equations for a "smooth" asymmetric focusing channel // J. Appl. Phys. 2004, v. 96, № 1, p. 784790 .

43. I.L. Sheynman, A. Kanareykin. Definition of Focusing System Parameters on the Basis of the Analysis of a Transverse Bunch Dynamics in Dielectric Loaded Wakefield Accelerator // Proc. IPAC'10, Kyoto, Japan, 2009, p. 4416-4418.

44. A.J.W. Reitsma, V.V. Goloviznin, L.P.J. Kamp, T.J. Schep. Bunch Self-Focusing Regime of Laser Wakefield Acceleration with Reduced Emittance Growth // Phys. Rev. Lett. 2002, v. 88, № 1, p. 014802.

45. C.B. Schroeder, J.S. Wurtele. Particle Beam Stability in the Hollow Plasma Channel Wake Field Accelerator // CP569, Advanced Accelerator Concepts: Ninth Workshop. 2000, p. 616-629.

46. J.B. Rosenzweig, et al. Acceleration and Focusing of Electrons in Two-Dimensional Nonlinear Plasma Wake Fields // Phys. Rev. A. 1991, v. 44, № 10, p. R6190-R6192.

47. K.V. Lotov. Simulation of Ultrarelativistic Beam Dynamics in Plasma Wakefield Accelerator // Phys. Plasmas. 1998, v. 5, № 3, p. 785-791.

Article received 22.01.2020

\section{ОДНОРОДНОЕ ФОКУСИРУЮЩЕЕ ПОЛЕ ДЛЯ КОРОТКИХ РЕЛЯТИВИСТСКИХ ЭЛЕКТРОННЫХ СГУСТКОВ В ПЛАЗМЕ}

\section{В.И. Маслов, И.П. Левчук, Д.С. Бондар, И.Н. Онищенко}

Аналитически и численным моделированием исследуется кильватерная плазменная линза, в которой все короткие релятивистские электронные сгустки последовательности фокусируются одинаково и однородно. Для двух типов линз сформулированы и проверены численным моделированием необходимые для этого параметры фокусируемой последовательности релятивистских электронных сгустков.

\section{ОДНОРДНЕ ФОКУСУЮЧЕ ПОЛЕ ДЛЯ КОРОТКИХ РЕЛЯТИВІСТСЬКИХ ЕЛЕКТРОННИХ ЗГУСТКІВ У ПЛАЗМІ}

В.І. Маслов, І.П. Левчук, Д.С. Бондар, І.М. Оніщенко

Аналітично та числовим моделюванням досліджується плазмова кільватерна лінза, в якій усі короткі релятивістські електронні згустки послідовності фокусуються однаково та однорідно. Для двох типів лінз сформульовані та перевірені числовим моделюванням необхідні для цього параметри послідовності релятивістських електронних згустків, які фокусуються. 